\title{
The effect of sublethal concentrations of deltamethrin and alphacypermethrin on the fecundity and development of Ixodes ricinus (Acari: Ixodidae) eggs and larvae
}

\author{
Alicja Buczek ${ }^{1}$ - Katarzyna Bartosik ${ }^{1}$ (D) Weronika Buczek ${ }^{1} \cdot$ Alicja M. Buczek $^{1}$. \\ Paweł Kuczyński ${ }^{1,2}$
}

Received: 1 December 2018 / Accepted: 13 May 2019 / Published online: 29 May 2019

(C) The Author(s) 2019

\begin{abstract}
Two pyrethroids, deltamethrin (D) and alphacypermethrin (AC), have been used as commercial products for tick control worldwide. However, the effects of sublethal doses of these compounds on various tick species and their developmental stages have not been fully explored yet, although such knowledge could contribute to a more effective application of both pyrethroids and simultaneous reduction of their costs and undesirable side effects, including the harmful impact on other organisms and environmental contamination. This study investigates the effect of sublethal concentrations of D and AC applied to engorged females on the fecundity, development of eggs and larvae, and the number of offspring in the Ixodes ricinus (L.) tick, which is the most important vector of tick-borne diseases of humans in Europe. After detachment from rabbit's skin, fully engorged I. ricinus females were treated with $20 \mu \mathrm{l}$ of pyrethroid solutions at five concentrations from 0.01562 to $0.25 \%$ and kept at $28{ }^{\circ} \mathrm{C}$ and $75 \%$ relative humidity. The impact of the pyrethroids on maturation and development of eggs as well as development of larvae was assessed based on parameters of the preoviposition and oviposition periods and the course of embryogenesis and egg hatch. The investigations have shown that both tested acaricides reduce the reproductive rate in I. ricinus females by inhibition of egg development and disturb embryonic development and larval hatch. Females did not lay eggs at concentrations higher than $0.0625 \%$ AC and $0.125 \%$ D. The lower concentrations of both pyrethroids disturbed or inhibited the embryogenesis and egg hatch in I. ricinus.
\end{abstract}

Keywords Alphacypermethrin · Deltamethrin · Pyrethroids · Vector control · Tick control · Tick reproduction

Alicja Buczek

alicja.buczek@umlub.pl

1 Chair and Department of Biology and Parasitology, Medical University of Lublin, Radziwiłłowska 11 St., 20-080 Lublin, Poland

2 Chair and Department of Rehabilitation and Orthopaedics, Medical University of Lublin, Jaczewskiego 8 St, 20-090 Lublin, Poland 


\section{Introduction}

Given the direct effects of their parasitism and ability to transmit numerous pathogens, ticks represent arthropods with the greatest medical and epidemiological importance. The economic losses related to the detrimental effect exerted by ticks on livestock are very high (Jongejan and Uilenberg 2004; Ghosh et al. 2006; Ghosh and Nagar 2014). For instance, the annual expenditure related to ticks and animal tick-borne diseases are estimated at US\$ 3.24 billion in Brazil (Grisi et al. 2014), US\$ 573.61 million in Mexico (Rodriguez-Vivas et al. 2017), and US\$ 498.7 million in India (Minjauw and McLeod 2003). The costs of diagnostics and treatment of human tick-borne diseases, the incidence of which has risen in the recent decade, are substantial as well (Zhang et al. 2006; Müller et al. 2012). Therefore, investigations of the use of agents reducing tick population numbers in nature as control methods have aroused considerable interest.

The most common method for tick control is the use of acaricides, primarily pyrethroids that have been widely applied in the recent years. However, uncontrolled application of acaricides, disregarding the sensitivity of various developmental stages in individual species and the most efficient concentrations of the substances, contributes to development of resistance, which has been detected in some tick species (Mekonnen et al. 2002; Vatsya and Yadav 2011; Fernández-Salas et al. 2012; Abbas et al. 2014; Lenka et al. 2016) and in different populations of the same species (Sharma et al. 2012; Shyma et al. 2012; Abbas et al. 2014). Identification of the mode of action of different concentrations of chemical compounds against various tick species and their developmental stages is important for determination of their most effective dose reducing tick abundance and ensuring the lowest level of environmental contamination. The use of an appropriate acaricide dose is particularly important for the control of sympatric tick species, e.g. Ixodes ricinus (L.) and Dermacentor reticulatus (Fabricius) (Hubálek et al. 2003; Széll et al. 2006; Buczek and Bartosik 2011; Švehlová et al. 2014; Hofmeester et al. 2016; Stańczak et al. 2016; Olivieri et al. 2017; Radzijevskaja et al. 2018) and for minimisation of their harmful effects on other organisms present in the same ecosystem (Soderlund et al. 2002; Bradberry et al. 2005; Anadón et al. 2009; Antwi and Reddy 2015).

The aim of the present study was to determine remote effects of application of various concentrations of two pyrethroids, i.e. deltamethrin and alphacypermethrin, on engorged $I$. ricinus females and to establish the most efficient concentrations of the acaricides that will result in reduction of the abundance of tick offspring. Identification of the mechanism of action of acaricides on I. ricinus ticks has practical importance, as this species is widely distributed in Europe across forest and recreational areas, where it infests a variety of animal species and humans. I. ricinus plays the most prominent role in the transmission of many pathogens, e.g. Borrelia burgdorferi sensu lato and tick-borne encephalitis virus (Estrada-Peña and Jongejan 1999; Jensen et al. 2017). It also causes skin lesions and systemic reactions in the host (Bartosik et al. 2011a; Wilhelmsson et al. 2013), and mammalian meat allergy (alpha-gal syndrome) (Commins et al. 2011; Nuñez et al. 2011; Fischer et al. 2014).

\section{Materials and methods}

\section{Tick maintenance}

Unfed adult stages of I. ricinus were collected from vegetation by flagging in eastern Poland (Lubycza Królewska, $23^{\circ} 31^{\prime} \mathrm{E} 50^{\circ} 20^{\prime} \mathrm{N}$ ) during the spring activity peak of this 
species (from April to May). Prior to the application of the acaricides, the ticks were kept in glass containers at approximately $90 \%$ humidity in the laboratory. Only intact ticks that were active over a few post-collection days were used in the experiments. Subsequently, 15 females and 5 males were placed on shaved skin of an albino New Zealand rabbit (Oryctolagus cuniculus) kept at room temperature of ca. $20{ }^{\circ} \mathrm{C}$ and ca. $50 \%$ humidity. The presence of the males guaranteed fertilization of each female, since mating in this species can take place both away from the host and on the host. The course of feeding was assessed daily at the same time. Immediately after detachment from rabbit skin, each engorged I. ricinus female was weighed using a digital analytical laboratory balance with an accuracy of $0.01 \mathrm{mg}$ (RADWAG XA WPA 120/C/1) and transferred to a rearing chamber lined with Whatman filter paper discs. 134 females and 45 males were used in the examinations. Rabbits used in the experiment were provided with drinking water and commercial pellet food ad libitum.

\section{Test procedure}

Just after detachment engorged I. ricinus females placed in separate rearing chambers were treated with $20 \mu \mathrm{l}$ of the pyrethroid solutions using a $0.2-50 \mu 1$ micropipette with an accuracy of $0.5-2 \%$. The rearing chambers with the females were placed in the dark at a temperature of $28{ }^{\circ} \mathrm{C}$ and $75 \% \mathrm{RH}$ before and during oviposition. As shown in our investigations, maintenance of a temperature of $28{ }^{\circ} \mathrm{C}$ during rearing of I. ricinus ticks, which prefer high humidity, reduces the risk of growth of mould fungi, which inhibit embryonic development of eggs and can lead to their death or the death of females before the end of oviposition (unpubl. data). After completion of oviposition, the $I$. ricinus females and eggs laid were weighed.

The course of embryonic development was assessed on the basis of the number of dead eggs, the number of dead embryos, and the number of larvae with developmental anomalies, larvae with hatching disturbances, and normal larvae, in accordance with criteria adopted in similar investigations of D. reticulatus (Buczek et al. 2013, 2014a). The same procedures as those employed in the acaricide treatment experiments were simultaneously applied in a control tick group, in which the females were treated with $20 \mu \mathrm{l}$ of water instead of the tested substances.

In each experimental group receiving the different acaricide doses and in the control group, selected characteristic features of the non-parasitic stage of engorged females, including the preoviposition and oviposition periods and the course of embryonic development and I. ricinus egg hatch, were assessed. On the basis of the results obtained, such parameters as preoviposition period (PP), egg laying frequency (ELF), female postoviposition weight (FPW), female oviposition weight loss (FOWL), egg mass weight (EMW), egg conversion factor (ECF), hatching frequency (HF), embryogenesis period (EP), and hatching success (HS) were determined as in our previous studies on D. reticulatus (Buczek et al. 2013, 2014a).

Additionally, in each egg batch, the percentage of dead eggs, eggs with developmental disturbances at various embryogenesis stages, as well as the number of larvae with morphological anomalies, larvae with abnormal hatching, and normal larvae were determined (Buczek et al. 2013). 


\section{Tested acaricides}

The activity of two synthetic pyrethroids, i.e. deltamethrin (D) (commercial name: K-Othrine 2.5 flow produced by Roussel Uclaf, France) and alphacypermethrin (AC) (commercial name: Alfasect 5SC, produced by ASPRAN s.c. Jaworzno, Poland), at the concentrations of $0.01562,0.03125,0.0625,0.125$, and $0.25 \%$ was tested (Table 1 ). The use of the same concentrations of the compounds as in our earlier studies on D. reticulatus facilitates comparison of the sensitivity of both tick species to these substances. The dose applied for one specimen contained in $20 \mu \mathrm{l}$ of the solution was calculated based on the concentrations of the pyrethroid solutions tested (Table 1).

\section{Statistical analysis}

STATISTICA 5 and Microsoft Excel XP were used to analyse the results. Analysis of the differences in the distribution of the results depending on the tick group tested was performed using the Mann-Whitney U test and Kruskal-Wallis H test.

\section{Results}

Eggs were laid by $I$. ricinus females treated with $0.01562-0.125 \%$ deltamethrin (doses $0.07812-0.625 \mu \mathrm{g} / \mathrm{specimen}$ ) and $0.01562-0.0625 \%$ alphacypermethrin solutions (doses 0.15625-0.625 $\mu \mathrm{g} / \mathrm{specimen)}$ (Figs. 1, 2). However, at the highest concentration of the $\mathrm{AC}$, the eggs were deformed; probably due to the abnormal development of egg casings, which disintegrated and released egg content, the determination of the number of eggs in the batch was impossible. The proportion of females capable of egg production decreased with the increasing concentrations of the tested substances (Figs. 3, 4). At the highest concentrations of deltamethrin and alphacypermethrin that did not deprive the females of the oviposition ability, only 42.9 and $14.3 \%$ of females, respectively, laid eggs (100\% in the control group).

The preoviposition period in I. ricinus was prolonged upon application of both pyrethroids. At the $0.01562 \%$ deltamethrin concentration $(0.07812 \mu \mathrm{g} / \mathrm{specimen})$, the eggs developed for $15.00 \pm 7.823$ days and at $0.125 \%$ as long as $28.333 \pm 8.963$ days (control $8.467 \pm 1.196$ days). The differences were statistically significant (Table 2 ). The H test confirmed the statistically significant differences in the length of the preoviposition period in the groups of females treated with the various concentrations of the active agent. Similar

Table 1 Quantity of active substance in 20 $\mu \mathrm{l}$ of a deltamethrin and alphacypermethrin solutions applied as a single dose (in $\mu \mathrm{g})$

\begin{tabular}{lll}
\hline $\begin{array}{l}\text { Concentration of the } \\
\text { solution }(\%)\end{array}$ & $\begin{array}{l}\text { Content of active substance in } 20 \mu \mathrm{l} \text { of } \\
\text { solution (in } \mu \mathrm{g})\end{array}$ \\
\cline { 2 - 3 } & Deltamethrin & Alphacypermethrin \\
\hline 0.01562 & 0.07812 & 0.1562 \\
0.03125 & 0.1562 & 0.3125 \\
0.0625 & 0.3125 & 0.625 \\
0.125 & 0.625 & 1.25 \\
0.250 & 1.25 & 2.50 \\
\hline
\end{tabular}




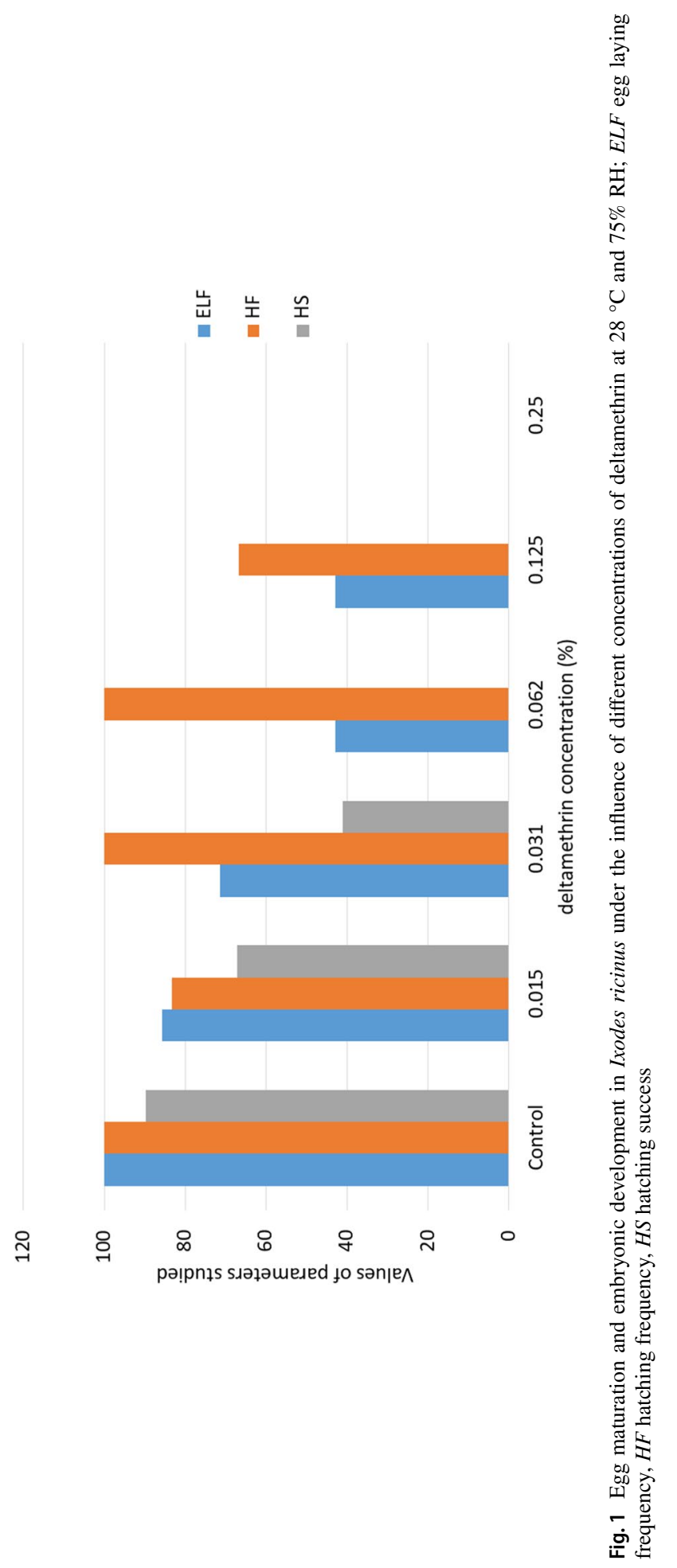




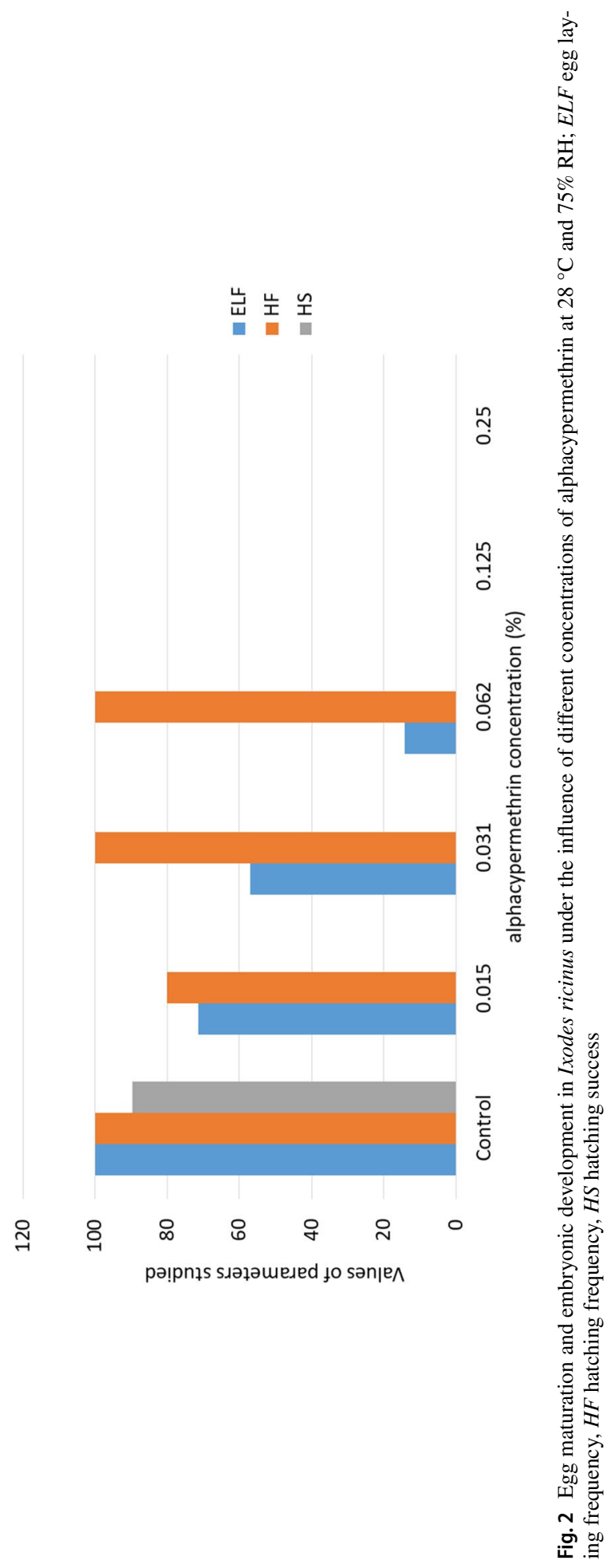




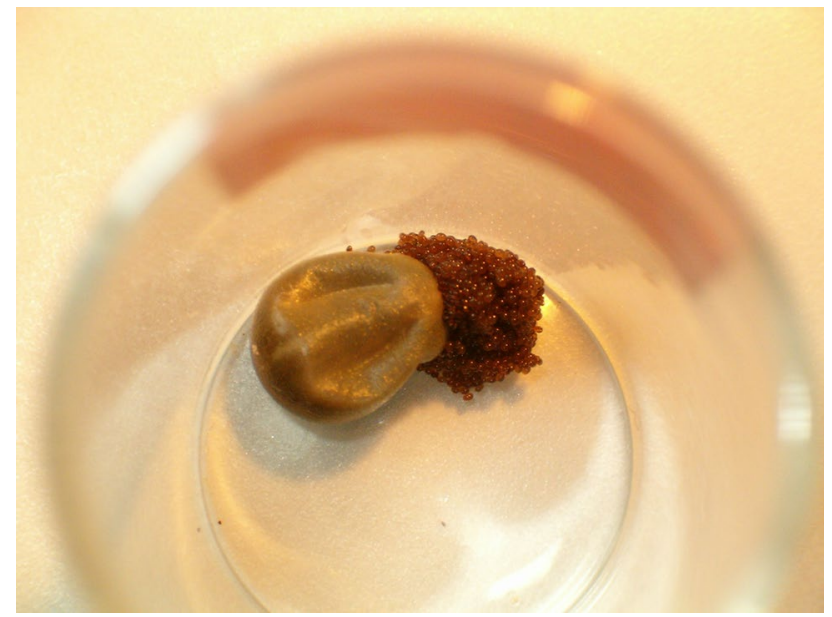

Fig. 3 Female and the egg batch of Ixodes ricinus after application of $0.01562 \%$ deltamethrin

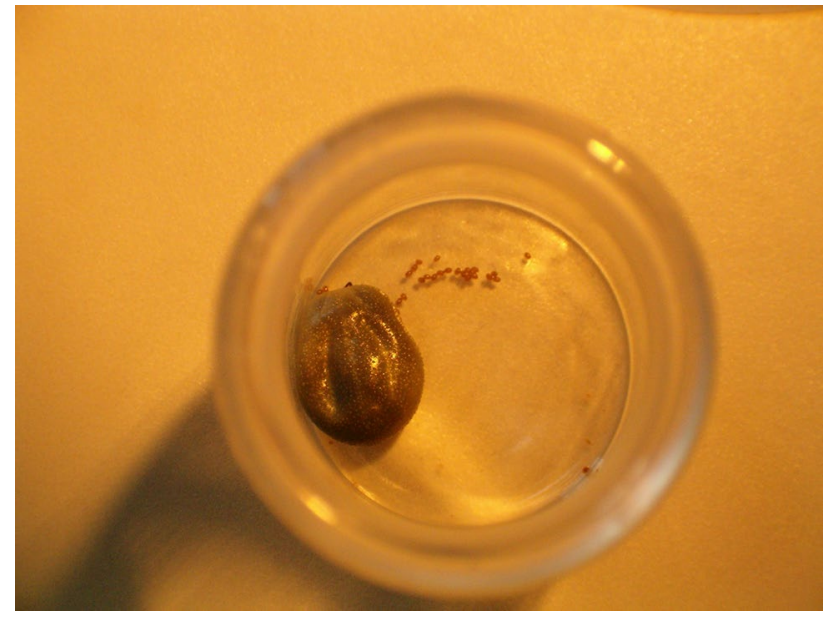

Fig. 4 Female and the egg batch of Ixodes ricinus after application of $0.0625 \%$ deltamethrin

trends were found in the alphacypermethrin treatment. The differences in the length of the preoviposition period induced by the action of the $0.01562 \%$ and $0.03125 \%$ AC solution $(0.1562$ and $0.3125 \mu \mathrm{g} / \mathrm{specimen}$, respectively) and that in the control group as well as the differences between the experimental groups treated with the different concentrations of AC were statistically significant (Table 2).

The mean number of eggs laid by the I. ricinus females decreased to 1664.5 and 1303.0 upon application of the lowest deltamethrin and alphacypermethrin concentrations, respectively (2615 eggs in the control group). The increasing concentrations of the substance reduced the number of eggs in the batch (Figs. 4, 5).

Deltamethrin concentrations higher than $0.125 \%(0.625 \mu \mathrm{g} / \mathrm{specimen})$ and alphacypermethrin concentrations exceeding $0.03125 \%(0.3125 \mu \mathrm{g} / \mathrm{specimen})$ inhibited the development of normal eggs. Both the egg mass weight and the egg conversion factor decreased 


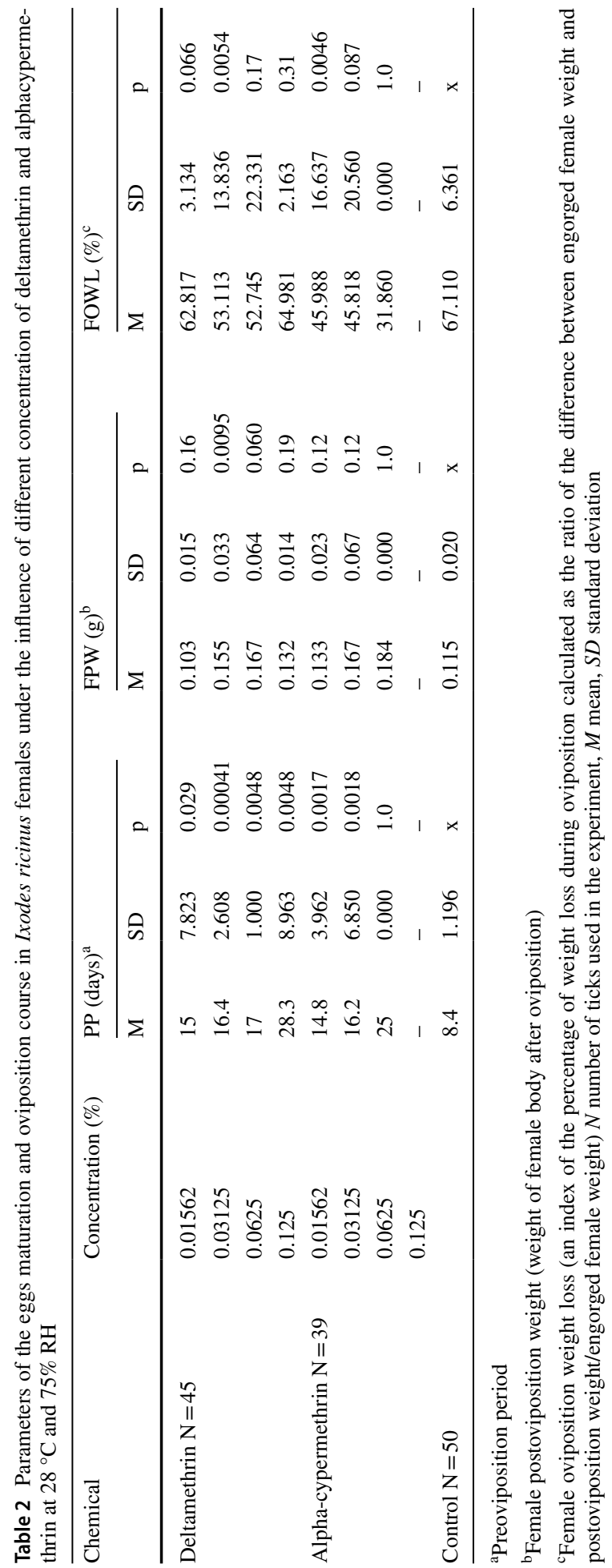




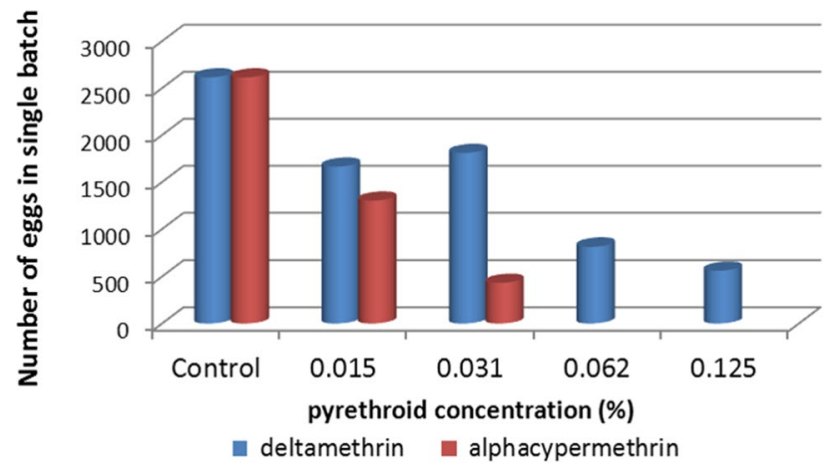

Fig. 5 Egg amount in Ixodes ricinus under the influence of different concentrations of deltamethrin and alphacypermethrin at $28^{\circ} \mathrm{C}$ and $75 \% \mathrm{RH}$

Table 3 Parameters of the eggs maturation and oviposition course in Ixodes ricinus females under the influence of different concentration of deltamethrin and alphacypermethrin at $28{ }^{\circ} \mathrm{C}$ and $75 \% \mathrm{RH}$

\begin{tabular}{|c|c|c|c|c|c|c|c|}
\hline \multirow[t]{2}{*}{ Chemical } & \multirow[t]{2}{*}{ Concentration (\%) } & \multicolumn{3}{|c|}{ EMW $(m g)^{a}$} & \multicolumn{3}{|l|}{$\mathrm{ECF}^{\mathrm{b}}$} \\
\hline & & M & SD & $\mathrm{p}$ & $\mathrm{M}$ & SD & $\mathrm{p}$ \\
\hline \multirow[t]{5}{*}{ Deltamethrin $\mathrm{N}=45$} & 0.01562 & 0.114 & 0.021 & 0.00082 & 0.415 & 0.093 & 0.030 \\
\hline & 0.03125 & 0.108 & 0.027 & 0.00097 & 0.322 & 0.078 & 0.0011 \\
\hline & 0.0625 & 0.087 & 0.049 & 0.0085 & 0.245 & 0.157 & 0.010 \\
\hline & 0.125 & 0.081 & 0.042 & 0.020 & 0.219 & 0.121 & 0.024 \\
\hline & 0.25 & - & - & - & - & - & - \\
\hline \multirow[t]{5}{*}{ Alpha-cypermethrin $\mathrm{N}=39$} & 0.01562 & 0.057 & 0.025 & 0.0 & 0.238 & 0.129 & 0.0028 \\
\hline & 0.03125 & 0.047 & 0.035 & 0.0 & 0.145 & 0.099 & 0.0016 \\
\hline & 0.0625 & 0.034 & 0.000 & 0.0 & 0.127 & 0.00 & 0.0 \\
\hline & 0.125 & - & - & - & - & - & - \\
\hline & 0.25 & - & - & - & - & - & - \\
\hline Control $\mathrm{N}=50$ & & 0.187 & 0.031 & $\mathrm{x}$ & 0.537 & 0.109 & $\mathrm{x}$ \\
\hline
\end{tabular}

${ }^{a}$ Egg mass weight - the total weight of eggs laid by a female

${ }^{\mathrm{b}}$ Egg conversion factor-engorged female weight used for egg production, $N$ number of ticks used in the experiment, $M$ mean, $S D$ standard deviation

statistically significantly compared with the control group and decreased with the increasing concentration of the two tested substances (Table 3). The different concentrations of deltamethrin and alphacypermethrin caused statistically significant changes in the female postoviposition weight and in the indicator of female oviposition weight loss (Table 2).

The pyrethroids tested disturbed the course of the embryonic development of I. ricinus eggs (Table 4). Statistically significant differences in the length of the embryonic development period were found upon application of $0.03125 \%$ deltamethrin as well as 0.01562 and $0.031255 \%$ alphacypermethrin, compared with the control (Table 4). The $\mathrm{H}$ test revealed a statistically significant difference in the length of embryogenesis between the experimental groups treated with the different alphacypermethrin concentrations.

Normal larvae only hatched in experiments in which I. ricinus females were treated with the 0.01562 and $0.03125 \%$ deltamethrin solutions $(67.07$ and $41.14 \%$ of larvae, 
respectively; control $89.64 \%$ ). In these experimental conditions, the embryonic development of a substantial proportion of eggs was impaired at various stages, and egg death in embryogenesis stage I, II, and III, larvae trapped in the egg casing (Fig. 6), and larvae with morphological anomalies were noted (Table 5). Even more serious disturbance in the course of the initial stage of embryonic development was observed when the higher deltamethrin concentrations were applied. No normal larvae hatched and all eggs died soon after oviposition as a result of application of each alphacypermethrin concentration.

\section{Discussion}

Ixodes ricinus is a three-host species with a 2.5-3-year-long developmental cycle in the temperate climate zone (Chmela 1969). The biological features of I. ricinus, i.e. high fertility (Bartosik and Buczek 2012), an ability to adapt to various types of habitats and abiotic conditions (Bartosik et al. 2011b; Geller et al. 2013; Pangrácová et al. 2013; Buczek et al. 2014b), and a wide host range including numerous small and big mammals and birds (Gern 2008), contribute to changes in their distribution range and increased abundance of this tick species (Jaenson et al. 2012; Medlock et al. 2013). The expansion of the I. ricinus occurrence range was facilitated by climatic and weather changes as well as human activities influencing groups of plants and animals that are potential hosts of various developmental stages of this tick species (Estrada-Peña et al. 2006; Gray 2008; Schwarz et al. 2009; Buczek et al. 2014b).

Application of effective acaricides at time intervals controlled by environmental monitoring over a given area may substantially reduce the abundance of the tick species (Benelli et al. 2017), thereby mitigating the risk of tick-borne diseases (Pegram and Eddy 2003; Otranto et al. 2010). However, application of acaricides may lead to development of tick cross-resistance to chemical compounds with a similar mode of action or even multiple resistance to several chemical compounds with different mechanisms of activity (Sutherst and Comins 1979; George et al. 2004; Abbas et al. 2014). The development of acaricide

Table 4 Embryogenesis period in Ixodes ricinus under the influence of different concentration of deltamethrin and alphacypermethrin at $28^{\circ} \mathrm{C}$ and $75 \% \mathrm{RH}$

\begin{tabular}{lllll}
\hline Chemical & Concentration $(\%)$ & \multicolumn{3}{l}{$\mathrm{EP}(\text { days })^{\mathrm{a}}$} \\
\cline { 3 - 5 } & & $\mathrm{M}$ & $\mathrm{SD}$ & $\mathrm{p}$ \\
\hline Deltamethrin & 0.01562 & 33.2 & 7.259 & 0.14 \\
$\mathrm{~N}=45$ & 0.03125 & 32.6 & 1.949 & 0.038 \\
& 0.0625 & 31 & 1.000 & 0.38 \\
& 0.125 & 30.5 & 3.536 & 0.82 \\
Alphacypermethrin & 0.01562 & - & - & - \\
$\mathrm{N}=39$ & 0.03125 & 35.7 & 5.909 & 0.022 \\
& 0.0625 & 37.5 & 6.028 & 0.013 \\
& 0.125 & 36 & 0.00 & 1.0 \\
Control N=50 & 0.25 & - & - & - \\
\hline
\end{tabular}

${ }^{a}$ Embryogenesis period: period between the beginning of oviposition to hatching of the first larva, $N$ number of ticks used in the experiment, $M$ mean, $S D$ standard deviation 


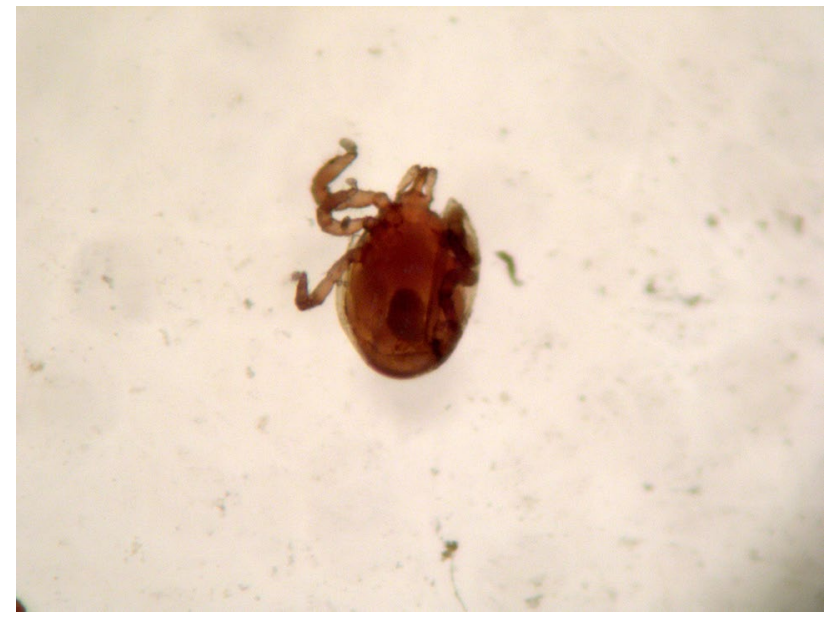

Fig. 6 Ixodes ricinus larva trapped in the egg casing

resistance in ticks is influenced by many factors, e.g. the structure and dose of chemicals, mode of application of the formulations, frequent use of the same tick control product for a long time, and use of the chemical substances for other purposes, e.g. for pest control. Given the possibility of resistance in ticks, the use of sublethal acaricide doses, similar to those tested in this study, should be monitored and resistance management practices with integrated actions in tick control should be applied in the area of where the chemicals are used (Kunz and Kemp 1994; Ghosh et al. 2006; Stafford et al. 2017). In turn, reduced concentrations of acaricides introduced to tick habitats and/or applied to tick hosts increase the degree of environmental contamination and the negative effect on other organisms (Kunz and Kemp 1994; Soderlund et al. 2002; Das and Mukherjee 2003; Antwi and Reddy 2015; Glorennec et al. 2017). The use of a reduced amount of active substances in formulations has economic importance as well, as it lowers the high costs of the control of ticks and tickborne diseases (Ostfeld et al. 2006; Stafford et al. 2017). Acaricides with various chemical structures and different toxicities have been used for I. ricinus control on the host (e.g. Henderson and Stevens 1987; Taylor and Elliott 1987; Mehlhorn et al. 2011; Wengenmayer et al. 2014) and away from the host (e.g. Rupeš et al. 1972; Bogachkina et al. 2011). However, only few investigations were focused on assessment of the effects of application of sublethal pyrethroid doses on female reproductive performance and embryonic development in this species (Buczek et al. 2014c). Such investigations are particularly advisable since, due to the slow rate of development of tick poisoning, unfed ticks are able to infest a host and ingest its blood, engorged females are capable of oviposition, and engorged young stages are able to moult into successive developmental stages. The phenomenon of "overcoming the poisoning" in ticks may contribute to sustenance of interspecific and intraspecific pathogen transmission (Uspensky and Ioffe-Uspensky 2006).

Our investigations indicate that the detrimental effect of the tested deltamethrin and alphacypermethrin pyrethroids applied during the preoviposition period can markedly reduce the abundance of $I$. ricinus offspring. The treatment of engorged females even with the lowest $0.01562 \%$ solutions of deltamethrin $(0.07812 \mu \mathrm{g} / \mathrm{specimen})$ and alphacypermethrin $(0.1562 \mu \mathrm{g} / \mathrm{specimen})$ extended the preoviposition period 1.78 - and 1.76 -fold, respectively, compared with the control. The highest concentrations of the tested substances, i.e. 


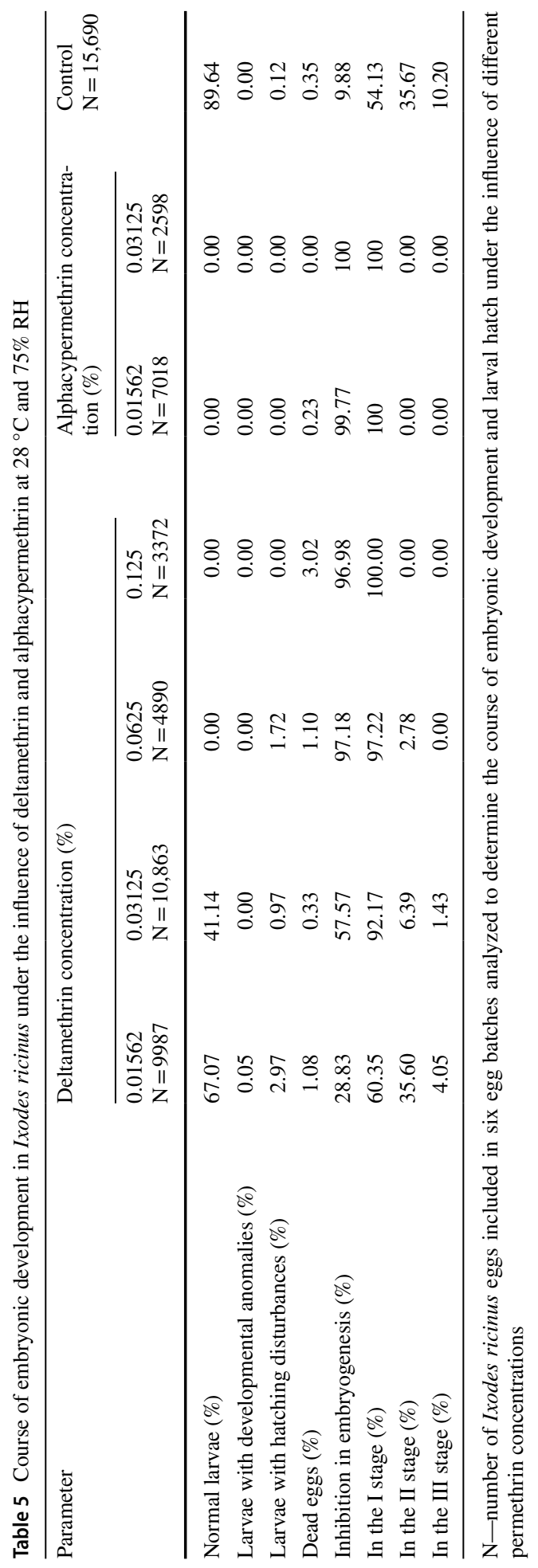


$0.125 \%$ deltamethrin $(0.625 \mu \mathrm{g} / \mathrm{specimen})$ and $0.0625 \%$ alphacypermethrin $(0.625 \mu \mathrm{g} / \mathrm{spec}-$ imen), lead to even more pronounced extension, 3.3- and 2.9-fold respectively, of the preoviposition period. Due to the disturbed course of maturation and egg development, a lower number of females were capable of oviposition, and the number of eggs in batches declined considerably. In this stage of the I. ricinus life cycle, alphacypermethrin proved to be a potent agent, whose lowest concentrations of $0.01562 \%(0.1562 \mu \mathrm{g} / \mathrm{specimen})$ decreased the number of eggs in batches by half, whereas the concentration of $0.03125 \%(0.3125 \mu \mathrm{g} /$ specimen) caused a six-fold reduction compared with the control. On the average, the egg mass weight decreased over three times and the egg conversion factor declined over two times when the females were treated with alphacypermethrin. Davey et al. (1998) reported that another pyrethroid fipronil reduced the weight of feeding females and their eggs in the one-host tick Rhipicephalus (Boophilus) microplus (Canestrini).

Our results correspond with the investigations carried out by other authors (Friesen and Kaufman 2003; Oliveira et al. 2008; Roma et al. 2010; Camargo-Mathias et al. 2017), who demonstrated cytotoxic effects of pyrethroids on the tick reproductive system. Cypermethrin inhibited oocyte development in Amblyomma hebraeum Koch (Friesen and Kaufman 2003). In semi-engorged Rhipicephalus sanguineus (Latreille), fipronil induced changes in the number and size of oocytes, as well as changes in their structure (cytoplasm vacuolisation) (Oliveira et al. 2008). Similarly, in this species, permethrin induced a decrease in the oocyte size, appearance of large vacuoles in their cytoplasm, and a decline in the number of yolk granules (Roma et al. 2010).

As suggested by Balashov (1983) in a study of Hyalomma asiaticum Schulze et Schlottke, there are two (endogenous and exogenous) sources of yolk production in ticks. The ultrastructural analysis of $R$. sanguineus ovary shows that endogenous yolk synthesis begins in oocytes II, and the number of yolk granules increases in the successive stages of oocyte development (III-IV) (Oliveira et al. 2005). In turn, the exogenous sources of yolk probably include both the fat body (in whose cells vitellogenic proteins are secreted into the hemolymph) (Sonenshine 1991) and the pedicel cells (Oliveira et al. 2005).

Through their neurotoxic effect on ticks (Roma et al. 2010, 2013), pyrethroids impair synthesis and/or secretion of hormones regulating vitellogenin synthesis in argasid (Chinzei et al. 1989; Taylor et al. 1991) and ixodid ticks (Friesen and Kaufman 2002, 2003; Roma et al. 2012).

The substances disturbed the embryonic development in I. ricinus more severely, resulting in prolongation of this period and inhibition of the first stage of embryogenesis, as well as inhibited larval hatch and development of abnormal larvae.

The morphological anomalies in larval legs of I. ricinus such as oligomely (lack of appendages) or fusion of appendages on the same side of the idiosoma and the presence of larvae with hatch disturbances reported in the present study are similar to those found in ticks collected in Upper Silesia, a region highly contaminated with industrial waste (unpublished data), and those reared in laboratory conditions at various temperature ranges (Buczek 1992) and humidity conditions (Buczek 2000). In D. reticulatus tick larvae, morphological changes affecting walking legs, e.g. oligomely, leg fusion, or branching legs, were also induced by deltamethrin (Buczek et al. 2013) and permethrin (Buczek et al. 2014a). An interesting phenomenon of formation of an additional (fourth) pair of legs in D. silvarum Olenev hatched from eggs laid by females treated with DDT was reported by Ioffe (1984).

The results of these studies imply a role of the nitrile group (enhancing the amphiphilic nature of linkages) and halogen in the vinyl substituent in the pronounced teratologic effect of the pyrethroid on I. ricinus. It seems possible that, irrespective of the difference in the 
internal energy of the stereoisomeric forms, the type of the halogen determines the efficiency of the cellular of $\mathrm{N}$-alkylation processes. The alphacypermethrin molecule contains chlorine, whereas the deltamethrin molecule-bromine.

As in the case of I. ricinus, alphacypermethrin exerted a more potent toxic effect than deltamethrin on the development of eggs and larvae in $D$. reticulatus, another Palearctic tick species. However, a comparison of the current study and previous results obtained simultaneously (Buczek et al. 2013, 2014c) shows that the activity of the tested agents differs in both tick species. Treated with the same deltamethrin doses at all the concentrations ranging from 0.01562 to $0.125 \%$, fewer I. ricinus females laid eggs, compared with $D$. reticulatus females. In turn, the lowest doses of alphacypermethrin reduced the reproductive performance more efficiently in $D$. reticulatus than in I. ricinus females; however, it completely inhibited maturation and egg development only at the concentration of $0.25 \%$ (Buczek et al. 2014c).

Likewise in I. ricinus, alphacypermethrin inhibited egg embryonic development and larval hatch in D. reticulatus at the lowest $0.01562 \%$ concentrations (Buczek et al. 2013). The course of embryonic development upon application of deltamethrin differed in these species, hence the different proportions of dead eggs, abnormally hatched larvae, and normal larvae. In I. ricinus, $41.14 \%$ of normal larvae hatched at the $0.03125 \%$ concentration of deltamethrin and complete inhibition of larval hatch was noted at the concentration of $0.0625 \%$ of this substance. $0.01 \%$ cis-cypermethrin, $0.015 \%$ cypermethrin, and $0.0025 \%$ deltamethrin inhibited larval hatch in $R$. sanguineus in $72.1,67.3$, and $42.0 \%$, respectively (Bicalho et al. 2001).

The different effects of deltamethrin and alphacypermethrin on I. ricinus and D. reticulatus corroborate the need for assessment of the acaricidal effects of chemical compounds in various tick species. Uspensky and Ioffe-Uspensky (2006) found that the duration of poisoning development in adult tick females from several genera of ticks after acaricide application correlated with the degree of species-specific refractoriness. Tick age also exerts an effect on their sensitivity to chemical substances (Rupeš et al. 1972; Mount 1984; Uspensky and Ioffe-Uspensky 2006).

\section{Conclusion}

The investigations indicate that application of the tested compounds in appropriate sublethal doses can reduce the abundance of successive generations of I. ricinus, which may contribute to reduction of pathogen transmission in the population of this tick species. Given the necessity of minimisation of the toxic effects of chemical substances on the environment and reduction of the high costs of tick control, lower doses of alphacypermethrin and deltamethrin decreasing the abundance of tick offspring can be applied in I. ricinus control. Yet, this practice offers a possibility of development of tick resistance to these synthetic pyrethroids. Hence, in areas where low doses of synthetic pyrethroids are applied in tick control, it is particularly essential to monitor the efficacy of the chemicals and rigorous resistance management. It is also indispensible to develop a strategy for control of ticks and tick-borne diseases. 


\section{Compliance with ethical standards}

Conflict of interest The authors declare that they have no conflict of interest.

Ethical approval All applicable international, national, and/or institutional guidelines for the care and use of animals were followed. All procedures performed in studies involving animals were in accordance with the ethical standards of the institution or practice at which the studies were conducted (the study was approved from the Local Commission for Animal Experiments, Lublin, Poland).

Open Access This article is distributed under the terms of the Creative Commons Attribution 4.0 International License (http://creativecommons.org/licenses/by/4.0/), which permits unrestricted use, distribution, and reproduction in any medium, provided you give appropriate credit to the original author(s) and the source, provide a link to the Creative Commons license, and indicate if changes were made.

\section{References}

Abbas RZ, Zaman MA, Colwell DD, Gilleard J, Iqbal Z (2014) Acaricide resistance in cattle ticks and approaches to its management: the state of play. Vet Parasitol 203:6-20. https://doi.org/10.1016/j.vetpa r.2014.03.006

Anadón A, Martínez-Larrañaga MR, Martínez MA (2009) Use and abuse of pyrethrins and synthetic pyrethroids in veterinary medicine. Vet J 182:7-20. https://doi.org/10.1016/j.tvj1.2008.04.008

Antwi FB, Reddy GVP (2015) Toxicological effects of pyrethroids on non-target aquatic insects. Environ Toxicol Pharmacol 40:915-923. https://doi.org/10.1016/j.etap.2015.09.023

Balashov YS (1983) The female reproductive system. In: Balashov YS (ed) An atlas of ixodid ticks ultrastructure. Entomological Society of America, College Park, pp 98-128 (in Russian)

Bartosik K, Buczek A (2012) The impact of intensity of invasion of Ixodes ricinus and Dermacentor reticulatus on the course of the parasitic phase. Ann Agric Environ Med 19:651-655

Bartosik K, Lachowska-Kotowska P, Szymańska J, Wójcik-Fatla A, Pabis A, Buczek A (2011a) Environmental conditioning of incidence of tick-borne encephalitis in the south-eastern Poland in 1996-2006. Ann Agric Environ Med 18:119-126

Bartosik K, Sitarz M, Szymańska J, Buczek A (2011b) Tick bites on humans in the agricultural and recreational areas in south-eastern Poland. Ann Agric Environ Med 18:151-157

Benelli G, Maggi F, Romano D, Stefanini C, Vaseeharan B, Kumar S, Higuchi A, Alarfaj AA, Mehlhorn H, Canale A (2017) Nanoparticles as effective acaricides against ticks—a review. Ticks Tick Borne Dis $8: 821-826$

Bicalho KA, Ferreira F, Borges LM, Ribeiro MFB (2001) In vitro evaluation of the effects of some acaricides on Rhipicephalus sanguineus (Acari: Ixodidae). Arq Bras Med Vet Zootec 53:548-552

Bogachkina S, Rakitin I, Meltser A, Parkov O, Chindzheria I, Antyikova L, Datskevich A (2011) Importance of acaricide treatment for prevention of natural focal infections of tick-borne encephalitis and Lyme borreliosis in St. Petersburg. J Netw Commun Dis Control North East Eur 12:76-82 (in Russian)

Bradberry SM, Cage SA, Proudfoot AT, Vale JA (2005) Poisoning due to pyrethroids. Toxicol Rev 24:93-106

Buczek A (1992) Studies on the biology of Argas (A.) reflexus (Fabricius, 1794) (Acari: Ixodida: Argasidae). 2. Effect of altering temperatures on embryonic development and egg hatch. Fol Biol 40:151-153

Buczek A (2000) Experimental teratogeny in the tick Hyalomma marginatum marginatum (Acari: Ixodida: Ixodidae): effect of high humidity on embryonic development. J Med Entomol 37:807-814. https://doi. org/10.1603/0022-2585-37.6.807

Buczek A, Bartosik K (2011) Ticks (Ixodida: Ixodidae, Amblyommidae) in south-eastern Poland and their medical and epidemiological importance. Zdr Publ 121:392-397

Buczek A, Bartosik K, Kuczyński P (2013) Evaluation of the effect of various concentrations of selected pyrethroids on the development of Dermacentor reticulatus eggs and larvae. Ann Agric Environ Med 20:447-451

Buczek A, Bartosik K, Kuczyński P (2014a) Sensitivity to permethrin in a Dermacentor reticulatus population from eastern Poland in laboratory study. Parasit Vectors 7:18. https://doi. org/10.1186/1756-3305-7-18 
Buczek A, Bartosik K, Kuczyński P (2014b) The toxic effect of permethrin and cypermethrin on engorged Ixodes ricinus females. Ann Agric Environ Med 21:259-261

Buczek A, Ciura D, Bartosik K, Zając Z, Kulisz J (2014c) Threat of attacks of Ixodes ricinus ticks (Ixodida: Ixodidae) and Lyme borreliosis within urban heat islands in south-western Poland. Parasit Vectors 7:562. https://doi.org/10.1186/s13071-014-0562-y

Camargo-Mathias MI, Pereira NRC, da Silva Reis C, de Almeida CR, dos Santos Mendes DR, de Araújo GB, Postali L, Figueroa T, Ferreira ARF, Santos JP, de Oliveira PR (2017) Deltamethrin as inductor agent of precocious ovarian degeneration in Rhipicephalus sanguineus s.l. (Acari: Ixodidae) ticks. Exp Appl Acarol 72:161-169. https://doi.org/10.1007/s10493-017-0144-8

Chinzei Y, Itoh K, Ando K (1989) Cypermethrin induction of vitellogenesis and ovarian development in unfed adult female Ornithodoros moubata (Acari: Argasidae). Invertebr Reprod Dev 15:19-26

Chmela J (1969) On the development cycle of the common tick (Ixodes ricinus L.) in the North-Moravian natural focus of tick-borne encephalitis. Folia Parasitol 16:313-319

Commins SP, James HR, Kelly LA, Pochan SL, Workman LJ, Perzanowski MS, Kocan KM, Fahy JV, Nganga LW, Ronmark E, Cooper PJ, Platts-Mills TA (2011) The relevance of tick bites to the production of IgE antibodies to the mammalian oligosaccharide galactose- $\alpha-1,3$-galactose. J Allergy Clin Immunol 127:1286-1293. https://doi.org/10.1016/j.jaci.2011.02.019

Das BK, Mukherjee SC (2003) Toxicity of cypermethrin in Labeo rohita fingerlings: biochemical, enzymatic and haematological consequences. Comp Biochem Physiol C 134:109-121

Davey RB, Ahrens EH, George JE, Hunter JS, Jeannin P (1998) Therapeutic and persistent efficacy of fipronil against Boophilus microplus (Acari: Ixodidae) on cattle. Vet Parasitol 74:261-276

Estrada-Peña A, Jongejan F (1999) Ticks feeding on humans: a review of records on human-biting Ixodoidea with special reference to pathogen transmission. Exp Appl Acarol 23:685-715

Estrada-Peña A, Venzal JM, Sánchez Acedo C (2006) The tick Ixodes ricinus: distribution and climate preferences in the western Palaearctic. Med Vet Entomol 20:189-197

Fernández-Salas A, Rodriguez-Vivas RI, Alonso-Diaz MA (2012) Resistance of Rhipicephalus microplus to amitraz and cypermethrin in tropical cattle farms in Veracruz, Mexico. J Parasitol 98:1010-1014

Fischer J, Hebsaker J, Caponetto P, Platts-Mills TA, Biedermann T (2014) Galactosealpha-1,3-galactose sensitization is a prerequisite for pork-kidney allergy and cofactor-related mammalian meat anaphylaxis. J Allergy Clin Immunol 134:755-759. https://doi.org/10.1016/j.jaci.2014.05.051

Friesen KJ, Kaufman WR (2002) Quantification of vitellogenesis and its control by 20-hydroxyecdysone in the ixodid tick, Amblyomma hebraeum. J Insect Physiol 48:773-782

Friesen KJ, Kaufman WR (2003) Cypermethrin inhibits egg development in the ixodid tick, Amblyomma hebraeum. Pestic Biochem Physiol 76:25-35

Geller J, Nazarova L, Katargina O, Golovlijova I (2013) Borrelia burgdorferi sensu lato prevalence in tick populations in Estonia. Parasit Vectors 6:202

George JE, Pound JM, Davey RB (2004) Chemical control of ticks on cattle and the resistance of these parasites to acaricides. Parasitology 129:S353-S366

Gern L (2008) Borrelia burgdorferi sensu lato, the agent of Lyme borreliosis: life in the wilds. Parasite $15: 244-247$

Ghosh S, Nagar G (2014) Problem of ticks and tick-borne diseases in India with special emphasis on progress in tick control research: a review. J Vector Borne Dis 51:259-270

Ghosh S, Azhahianambi P, de la Fuente J (2006) Control of ticks of ruminants, with special emphasis on livestock farming systems in India: present and future possibilities for integrated control—a review. Exp Appl Acarol 40:49-66

Glorennec P, Serrano T, Fravallo M, Warembourg C, Monfort C, Cordier S, Viel JF, Gléau FL, Bot BL, Chevrier C (2017) Determinants of children's exposure to pyrethroid insecticides in western France. Environ Int 104:76-82

Gray JS (2008) Ixodes ricinus seasonal activity: implications of global warming indicated by revisiting tick and weather data. Int J Med Microbiol 298:S19-S24

Grisi L, Leite RC, Martins JR, Barros AT, Andreotti R, Cançado PH, León AA, Pereira JB, Villela HS (2014) Reassessment of the potential economic impact of cattle parasites in Brazil. Rev Bras Parasitol Vet 23:150-156

Henderson D, Stevens DP (1987) Cypermethrin pour-on the control of ticks (Ixodes ricinus) on sheep. Vet Rec 121:317-319

Hofmeester TR, van der Lei P-B, van Leeuwen AD, Sprong H, van Wieren SE (2016) New foci of Haemaphysalis punctata and Dermacentor reticulatus in the Netherlands. Ticks Tick Borne Dis 7:367-370 
Hubálek Z, Halouzka J, Juøicová Z (2003) Host-seeking activity of ixodid ticks in relation to weather variables. J Vector Ecol 28:159-165

Ioffe ID (1984) Possible correlation between the reduction of legs IV in the larvae and development of the nervous apparatus in the Parasitiformes (Acarina). In: Griffiths DA, Bowman CE (eds) Acarology VI, vol 1. Ellis Horwood, Chichester, pp 286-294

Jaenson TGT, Jaenson DGE, Petersson E, Lindgren E (2012) Changes in the geographical distribution and abundance of the tick Ixodes ricinus during the past 30 years in Sweden. Parasit Vectors 5:8. https:// doi.org/10.1186/1756-3305-5-8

Jensen PM, Christoffersen CS, Moutailler S, Michelet L, Klitgaard K, Bødker R (2017) Transmission differentials for multiple pathogens as inferred from their prevalence in larva, nymph and adult of Ixodes ricinus (Acari: Ixodidae). Exp Appl Acarol 71:171-182. https://doi.org/10.1007/s10493-017-0110-5

Jongejan F, Uilenberg G (2004) The global importance of ticks. Parasitology 129:S3-S14

Kunz SE, Kemp DH (1994) Insecticides and acaricides: resistance and environmental impact. Rev Sci Tech Off Int Epiz 13:1249-1286

Lenka DR, Ravindran R, Jyothimol G, Udaykumar M, Reddy PMT, Sathish N, Palla I, Chandramohan B, Ajithkumar KG, Nair SN, Chandrasekhar L, Priya MN, Deepa CK, Sabu L, Juliet S, Ghosh S (2016) Deltamethrin resistance in south Indian isolates of Rhipicephalus (Boophilus) microplus. Vet Parasitol 5:37-41. https://doi.org/10.1016/j.vprsr.2016.09.002

Medlock JM, Hansford KM, Bormane A, Derdakova M, Estrada-Peña A, George JC, Golovljova I, Jaenson TG, Jensen JK, Jensen PM et al (2013) Driving forces for changes in geographical distribution of Ixodes ricinus ticks in Europe. Parasite Vectors 6:1. https://doi.org/10.1186/1756-3305-6-1

Mehlhorn H, Schumacher B, Jatzlau A, Abdel-Ghaffar F, Al-Rasheid KA, Klimpel S, Pohle H (2011) Efficacy of deltamethrin (Butox 7.5 pour on) against nymphs and adults of ticks (Ixodes ricinus, Rhipicephalus sanguineus) in treated hair of cattle and sheep. Parasitol Res 108:963-971. https://doi. org/10.1007/s00436-010-2141-2

Mekonnen S, Bryson NR, Fourie LJ, Peter RJ, Sickett AM, Taylor RJ, Strdom T, Horak IG (2002) Acaricide resistance profiles of single- and multi-host ticks from communal and commercial farming areas in the Eastern Cape and North-West Provinces of South Africa. Onderstepoort J Vet Res 69:99-105

Minjauw B, McLeod A (2003) Tick-borne diseases and poverty: the impact of ticks and tick-borne diseases on the livelihood of small scale and marginal livestock owners in India and eastern and southern Africa. Research report, DFID Animal Health Programme. Centre for Tropical Veterinary Medicine, University of Edinburgh, Edinburg, UK

Mount GA (1984) Effect of age, application date, and life stage on the susceptibility of free-living lone star ticks (Acari: Ixodidae) to acaricides. J Econ Entomol 77:1214-1218

Müller I, Freitag MH, Poggensee G, Scharnetzky E, Straube E, Schorerner CH, Hlobil H, Hagedorn HJ, Stanek G, Schubert-Unkmeir A, Norris DE, Gensichen J, Hunfeld KP (2012) Evaluating frequency, diagnostic quality and cost of Lyme borreliosis testing in Germany: a retrospective model analysis. Clin Dev Immunol 2912:595427. https://doi.org/10.1155/2012/595427

Nuñez R, Carballada F, Gonzalez-Quintela A, Gomez-Rial J, Boquete M, Vidal C (2011) Delayed mammalian meat-induced anaphylaxis due to galactose- $\alpha-1,3$-galactose in 5 European patients. J Allergy Clin Immunol 128:1122-1124. https://doi.org/10.1016/j.jaci.2011.07.020

Oliveira PR, Bechara GH, Denardi SE, Nunes ET, Camargo Mathias MI (2005) Morphological characterization of the ovary and oocytes vitellogenesis of the tick Rhipicephalus sanguineus (Latreille, 1806) (Acari: Ixodidae). Exp Parasitol 110:146-156

Oliveira PR, Bechara GH, Camargo-Mathias MI (2008) Evaluation of cytotoxic effects of fipronil on ovaries of semi-engorged Rhipicephalus sanguineus (Latreille, 1806) (Acari: Ixodidae) tick female. Food Chem Toxicol 46:2459-2465. https://doi.org/10.1016/j.fct.2008.03.034

Olivieri E, Gazzonis AL, Zanzani SA, Veronesi F, Manfredi MT (2017) Seasonal dynamics of adult Dermacentor reticulatus in a peri-urban park in southern Europe. Ticks Tick Borne Dis 8:772-779. https:// doi.org/10.1016/j.ttbdis.2017.06.002

Ostfeld RS, Price A, Hornbostel VL, Benjamin MA, Keesing F (2006) Controlling ticks and tick-borne zoonoses with biological and chemical agents. BioSci 56:383-394

Otranto D, De Caprariis D, Lia RP, Tarallo V, Lorusso V, Testini G, Dantas-Torres F, Latrofa S, Diniz PPVP, Mencke N et al (2010) Prevention of endemic canine vector-borne diseases using imidacloprid $10 \%$ and permethrin 50\% in young dogs: a longitudinal field study. Vet Parasitol 172:323-332

Pangrácová L, Derdáková M, Pekárik L, Hviščová I, Vichová B, Stanko M, Hlavatá H, Petko B (2013) Ixodes ricinus abundance and its infection with the tick-borne pathogens in urban and suburban areas of Eastern Slovakia. Parasit Vectors 6:238. https://doi.org/10.1186/1756-3305-6-238

Pegram RG, Eddy C (2003) Progress towards the eradication of Amblyomma variegatum from the Caribbean. Exp Appl Acarol 28:273-281 
Radzijevskaja J, Mardosaitè-Busaitienė D, Aleksandravičienė A, Paulauskas A (2018) Investigation of Babesia spp. in sympatric populations of Dermacentor reticulatus and Ixodes ricinus ticks in Lithuania and Latvia. Ticks Tick Borne Dis 9:270-274. https://doi.org/10.1016/j.ttbdis.2017.09.013

Rodriguez-Vivas RI, Grisi L, Pérez de León AA, Silva Villela H, Torres-Acosta JFJ, Fragoso Sánchez H, Romero Salas D, Rosario Cruz R, Saldierna F, García-Carrasco D (2017) Potential economic impact assessment for cattle parasites in Mexico review. Rev Mex Cienc Pecu 8:61-74

Roma GC, Furquim KCS, Bechara GH, Camargo-Mathias MI (2010) Permethrin-induced morphological changes in oocytes of Rhipicephalus sanguineus (Acari: Ixodidae) semi-engorged females. Food Chem Toxicol 48:825-830. https://doi.org/10.1016/j.fct.2009.12.016

Roma GC, Nunes PH, de Oliveira PR, Remédio RN, Bechara GH, Camargo-Mathias MI (2012) Central nervous system of Rhipicephalus sanguineus ticks (Acari: Ixodidae): an ultrastructural study. Parasitol Res 111:1277-1285. https://doi.org/10.1007/s00436-012-2962-2

Roma GC, Carmago-Mathias MI, Oliveira PR, Furquim KCS, Bechara GH (2013) Neurotoxic action of permethrin in Rhipicephalus sanguineus (Latreille, 1806)(Acari: Ixodidae) female ticks. Morphological and cytochemical evaluation of the central nervous system. Vet Parasitol 196:482-491. https://doi. org/10.1016/j.vetpar.2013.02.025

Rupeš V, Chmela J, Ledvinka J, Novák D, Tĕmin K, Hozák A, Sládková D (1972) The age of Ixodes ricinus ticks as a factor of their susceptibility to $p p$ '-DDT, imidan and carbaryl. Folia Parasitol 19:217-226

Schwarz A, Maier WA, Kistemann T, Kampen H (2009) Analysis of the distribution of the tick Ixodes ricinus L. (Acari: Ixodidae) in a nature reserve of western Germany using Geographic Information Systems. Int J Hyg Environ Health 212:87-96. https://doi.org/10.1016/j.ijheh.2007.12.001

Sharma AK, Kumar R, Kumar S, Nagar G, Singh NK, Rawat SS, Dhakad ML, Rawat AK, Ray DD, Ghosh S (2012) Deltamethrin and cypermethrin resistance status of Rhipicephalus (Boophilus) microplus collected from six agro-climatic regions of India. Vet Parasitol 188:337-345. https://doi.org/10.1016/j. vetpar.2012.03.050

Shyma KP, Kumar S, Sharma AK, Ray DD, Ghosh S (2012) Acaricide resistance status in Indian isolates of Hyalomma anatolicum. Exp Appl Acarol 58:471-481. https://doi.org/10.1007/s10493-012-9592-3

Soderlund DM, Clark JM, Sheets LP, Mullin LS, Piccirillo VJ, Sargent D, Stevens JT, Weiner ML (2002) Mechanisms of pyrethroid neurotoxicity: implications for cumulative risk assessment. Toxicology 171:3-59

Sonenshine D (1991) Biology of ticks, vol 1. Oxford University Press, New York

Stafford KC III, Williams SC, Molaei G (2017) Integrated pest management in controlling ticks and tickassociated diseases. J Integr Pest Manag 8(1):28. https://doi.org/10.1093/jipm/pmx018

Stańczak J, Biernat B, Matyjasek A, Racewicz M, Zalewska M, Lewandowska D (2016) Kampinos National Park: a risk area for spotted fever group rickettsioses, central Poland? Exp Appl Acarol 70:395-410. https://doi.org/10.1007/s10493-016-0083-9

Sutherst RW, Comins HN (1979) The management of acaricide resistance in the cattle tick, Boophilus microplus (Canestrini) (Acari: Ixodidae), in Australia. Bull Entomol Res 69:519-540

Švehlová A, Berthová L, Sallay B, Boldiš V, Sparagano OAE, Špitalská E (2014) Sympatric occurrence of Ixodes ricinus, Dermacentor reticulatus and Haemaphysalis concinna ticks and Rickettsia and Babesia species in Slovakia. Ticks Tick Borne Dis 5:600-605. https://doi.org/10.1016/j.ttbdis.2014.04.010

Széll Z, Sréter-Lancz Z, Márialigeti K, Sréter T (2006) Temporal distribution of Ixodes ricinus, Dermacentor reticulatus and Haemaphysalis concinna in Hungary. Vet Parasitol 141:377-379

Taylor SM, Elliott CT (1987) Deltamethrin and flumethrin pour-on formulations for the control of Ixodes ricinus on cattle. Vet Rec 120:278

Taylor D, Chinzei Y, Ito K, Higuchi N, Ando K (1991) Stimulation of vitellogenesis by pyrethroids in mated and virgin female adults, male adults, and fourth instar females of Ornithodoros moubata. J Med Entomol 28:322-329

Uspensky I, Ioffe-Uspensky I (2006) Potential risk of pathogen transmission by acaricide-poisoned ticks. Int J Med Microbiol 296:217-224. https://doi.org/10.1016/j.ijmm.2006.02.016

Vatsya S, Yadav CL (2011) Evaluation of acaricide resistance mechanisms in field populations of Rhipicephalus (Boophilus) microplus collected from India. Int J Acarol 37:405-410. https://doi. org/10.1080/01647954.2010.521518

Wengenmayer C, Williams H, Zschiesche E, Moritz A, Langenstein J, Roepke RK, Heckeroth AR (2014) The speed of kill of fluralaner (Bravecto ${ }^{\mathrm{TM}}$ ) against Ixodes ricinus ticks on dogs. Parasit Vectors 7:525. https://doi.org/10.1186/s13071-014-0525-3

Wilhelmsson P, Lindblom P, Fryland L, Nyman D, Jaenson TG, Forsberg P, Lindgren P-E (2013) Ixodes ricinus ticks removed from humans in Northern Europe: seasonal pattern of infestation, attachment sites and duration of feeding. Parasit Vectors 6:362. https://doi.org/10.1186/1756-3305-6-362 
Zhang X, Meltzer MI, Peña CA, Hopkins AB, Wroth L, Fix AD (2006) Economic impact of Lyme disease. Emerg Infect Dis 12:653-660

Publisher's Note Springer Nature remains neutral with regard to jurisdictional claims in published maps and institutional affiliations. 